Population Health Research Institute, St George's University of London, UK

2 Department of Surgery, Colchester Hospital, Essex, UK

3 Department of Primary Care and Public Health, School of Public Health Imperial College London, UK

4 National Institute for Health Research School of Primary Care Research, University of Manchester, UK

5 Harvard T H Chan School of Public Health, Harvard University, Boston, MA, USA

Correspondence to: M S Razai mrazai@sgul.ac.uk Cite this as: BMJ 2021;372:m4921 http://dx.doi.org/10.1136/bmi.m4921 Published: 14 January 2021

\title{
Mitigating ethnic disparities in covid-19 and beyond
}

\section{Although socioeconomic status partly explains ethnic disparities seen with covid-19, cultural and structural racism also adversely affect health, argue Mohammad Razai and colleagues}

\section{Mohammad S Razai, ${ }^{1}$ Hadyn K N Kankam, ${ }^{2}$ Azeem Majeed, ${ }^{3}$ Aneez Esmail, ${ }^{4}$ David R Williams}

The disproportionate effect of covid-19 on ethnic minorities in some high income countries throws into sharp relief the effects of racism on health. On almost all health measures, ethnic minority groups, especially black and South Asian people, have the worst outcomes. ${ }^{1-6}$ The covid-19 pandemic is just another example. ${ }^{7}$ This is a moral issue that has outraged civilised societies. As Alexandre Dumas wrote: "Moral wounds have this peculiarity-they may be hidden, but they never close; always painful, always ready to bleed when touched, they remain fresh and open in the heart."

The effects of racism and social determinants of health are intertwined. Racism both shapes social determinants of health and has its own effect on the health of ethnic minorities. To understand race and health, we must understand the role of ethnicity and racism within modern societies. Everyday acts of interpersonal discrimination, implicit biases, cultural and structural racism will over time lead to worse health outcomes, including higher rates of chronic diseases and lower life expectancy..$^{8-11}$

\section{Effect of covid-19 on ethnic minority groups}

Covid-19 has disproportionately affected ethnic minority groups in developed countries. In the UK, people of black ethnicity have had the highest diagnosis rates, with the lowest rates observed in white British people. ${ }^{7}$ Data up to May 2020 show $25 \%$ of patients requiring intensive care support were of black or Asian background. ${ }^{12}$

According to a Public Health England report, the mortality risk from covid-19 among ethnic minority groups is twice that of white British patients after potential confounding factors such as age, sex, income, education, housing tenure, and area deprivation have been taken into account. ${ }^{7}$ Data from covid-19 inpatients in England showed that South Asian people had the highest death rates $(350$ deaths/100o compared with 290/1000 for white people). ${ }^{13}$ Ethnic minority groups were also more likely to need intensive care and invasive ventilation than white patients despite similar disease severity on admission, similar duration of symptoms, and being younger with fewer comorbidities. ${ }^{13}$ Another study has shown a higher rate of covid-19 cases among ethnic minorities independent of comorbidities and socioeconomic risk factors. ${ }^{14}$

These differences are highlighted in the covid-19 cases among key workers. Although black and Asian staff represent only $21 \%$ of the NHS workforce, early analysis showed that they accounted for $63 \%$ of deaths among health and social care workers. ${ }^{15}$ This picture has also been reflected internationally. In the
US, the case and admission rates are at least 2.5 and 4.5 times higher, respectively, among black, Hispanic, and Native American populations compared with white populations. ${ }^{16}$ The American Public Media Research Laboratory has estimated a death rate of 61.6/100 ooo population for African Americans, 1.7 times greater than that of indigenous Americans and 2.3 times that of white and Asian Americans. ${ }^{17}$

\section{Possible causes of ethnic disparities in health outcomes}

Several potential reasons have been proposed, including higher rates of comorbidities (box 1) such as cardiovascular disease and diabetes in patients of South Asian ethnicity and hypertension in the black population. ${ }^{7}$

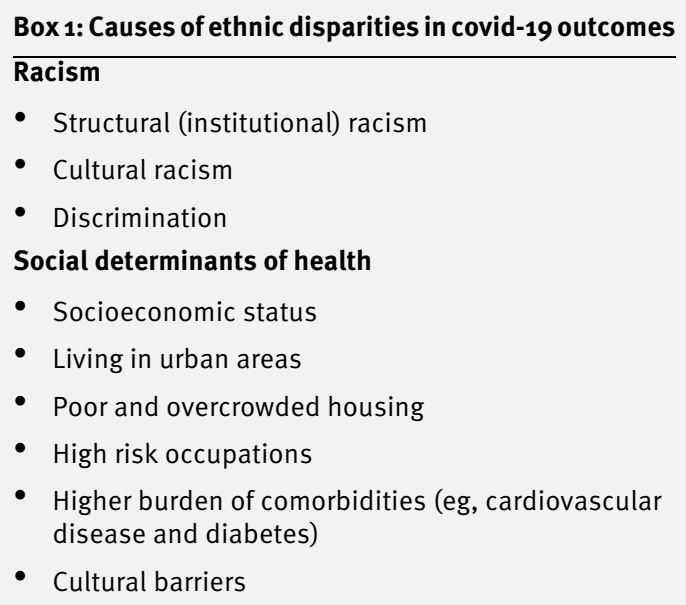

Ethnic minority groups are more likely to live in urban, overcrowded, and more deprived communities and to work in lower paid jobs, many of which carry a high risk of exposure to covid-19. ${ }^{718}$ Moreover, negative experiences within a culturally insensitive healthcare service may create barriers, inhibit access to healthcare, and influence healthcare seeking behaviours among ethnic minority groups. ${ }^{71}$ The UK government's report on ethnic disparities in covid-19 states that some of the excess risk remains unexplained despite accounting for socioeconomic and geographical factors such as occupational exposure, population density, household composition, and pre-existing health conditions. ${ }^{20}$

A Public Health England report found that racism and discrimination may have contributed to the increased risk of exposure to and death from covid-19 among ethnic minority groups. ${ }^{19}$ Ethnic minorities have poorer access to healthcare and poor experiences of care and treatment ${ }^{21}$ related to racial discrimination and marginalisation. ${ }^{8-11} 22$ 
Additionally, ethnic minority staff in the NHS are less likely to speak up and raise their concerns about testing and personal protective equipment. $^{23}$

However, ethnic disparities are not unique to covid-19 outcomes. Historically, marginalised ethnic groups have had higher rates and earlier onset of disease, more aggressive progression of disease, and poorer survival rates. ${ }^{6}$ Empirical analyses show that ethnic differences in health persist even after adjustment for socioeconomic status. In the UK, black women are five times more likely to die during pregnancy than white women ${ }^{24}$ and black people have a greater risk of detention under the Mental Health Act than white people. ${ }^{25}$ Research has also shown falling health in immigrant communities over time. For example, Mexican Americans and Mexican immigrants who had resided for 20 years or more in the US had a health profile similar to that of African Americans. ${ }^{26}$

Evidence accumulated over several decades shows that racism is a fundamental cause and driver of adverse health outcomes in ethnic minorities as well as inequities in health. ${ }^{8-11}$

Racism is a social construct that uses nationality, ethnicity, phenotypic, or other markers of social difference to maintain, capture, and justify the differential access to power and resources in society. ${ }^{27}$ It functions on multiple levels (box 2). ${ }^{9}$ Structural racism has the most deleterious effect on health. For example, a recent systematic review found that segregation was independently associated with late diagnosis and inferior survival rates in African Americans with lung or breast cancer. ${ }^{28}$ Although there are many forms of structural racism, residential segregation in the United States, including in its current form, is the most studied.

\section{Box 2: Definitions of racism ${ }^{9}$}

Racism
An organised social system in which the dominant ethnic group, based
on an ideology of inferiority, categorises and ranks people into social
groups or "races" and uses its power to devalue, disempower, and
differentially allocate valued societal resources and opportunities to
groups defined as inferior
Structural (institutional) racism
The processes of racism that are embedded in laws (local, state, and
federal), policies, and practices of society and its institutions that provide
advantages to ethnic groups deemed as superior, while differentially
oppressing, disadvantaging, or otherwise neglecting ethnic groups viewed
as inferior
Cultural racism
The instillation of the ideology of inferiority in the values, language,
imagery, symbols, and unstated assumptions of the larger society
Discrimination
- Individuals and larger institutions, deliberately or without intent, treat
ethnic groups differently, resulting in inequitable access to opportunities
and resources (eg, employment, education, and medical care)
- Self-reported discrimination-an awareness of experiences of
discrimination or bias that can adversely affect health, similar to other
psychosocial stressors

Segregation affects health in multiple ways. ${ }^{9}$ Firstly, it is responsible for ethnic differences in socioeconomic status. A US study showed that the elimination of segregation would eliminate ethnic differences in income, education, and unemployment and reduce ethnic differences in single motherhood by two thirds. ${ }^{29}$ All of these stark differences are driven by access to opportunity at the neighbourhood level. Less than $5 \%$ of black children live in neighbourhoods with good resources. Segregation has also been related to access to poorer quality education and employment opportunities. Segregation can also adversely affect health because it creates communities with poor quality housing and neighbourhood environments. The concentration of poverty in these areas leads to exposure to higher levels of multiple chronic and acute psychosocial stressors, greater clustering of these stressors, greater exposure to undesirable social and physical environmental conditions, and reduced access to a broad range of resources that enhance health.

Although levels of segregation are steady or falling in the US, they are rising in Europe, where it is driven primarily by religion. ${ }^{30}$ In the UK, Bangladeshi and Pakistani people are the most segregated groups. ${ }^{30}$ National data from 2015 also show that socially stigmatised ethnic groups are over-represented in the most deprived neighbourhoods in England. ${ }^{31} 32$ Just 9\% of white British people live in the most deprived $10 \%$ of neighbourhoods compared with $31 \%$ of Pakistani, $28 \%$ of Bangladeshi, $20 \%$ of black African, and $18 \%$ of black Caribbean people.

Cultural racism is a reliance on stereotypes. This can give rise to unconscious bias and have a detrimental effect on health. A major report in the US found overwhelming evidence that black and other minority people routinely received poorer quality of care than white people. ${ }^{33}$ For example, a retrospective study of 139 Hispanic and white American patients assessed the provision of analgesia for patients with long bone fractures. White patients were twice as likely to receive analgesia than Hispanic patients, even after consideration of individual patient and clinician characteristics and the types of injury. ${ }^{34}$ More recent research documents these patterns across a broad range of outcomes ${ }^{35}$ and that higher implicit bias scores among physicians are associated with biased treatment recommendations for black patients. ${ }^{36}$ Implicit biases can also affect the quality of patient interaction and non-verbal behaviour. For example, one study found that physicians who scored high on implicit bias had poorer quality communication with their patients on both patient and objective ratings. ${ }^{37}$

Some ethnic minority patients may process the negative stereotypes in their culture by accepting them as true. This endorsement of these negative views is called "internalised racism" and has been associated with multiple health outcomes, including psychological distress and obesity in black populations. ${ }^{38}$

A recent review of 29 literature reviews and meta-analyses published between 2013 and 2019 found multiple associations between self-reported discrimination and health. ${ }^{39}$ As well as poor mental health (mental disorders, psychological distress, and lower levels of psychological wellbeing), self-reported discrimination is associated with incident disease (eg, diabetes, hypertension, breast cancer, cardiovascular outcomes) and preclinical indicators of disease (eg, coronary artery calcification, visceral fat, heart rate variation, and inflammation), poor health behaviours (eg, binge eating, smoking, and substance use), and lower use of healthcare services and adherence to medical regimens. ${ }^{39}$

One mechanism by which ethnic discrimination affects health is weathering-whereby exposure to discrimination as well as psychosocial, physical, and chemical stressors erodes health and accelerates biological ageing. For example, black women's health deteriorates earlier than that of white women because of the constant stresses of their environment. ${ }^{40}$ Racism on a societal and individual level has both direct and indirect negative effects on health. It contributes to many of the causes of health disparities seen among ethnic groups. 


\section{Effect of racism on social determinants of health}

An analysis of early data on covid-19 suggests that both its incidence and effect are distributed unequally, affecting those with material and social deprivation the most. ${ }^{41}$ The Marmot review in England shows that health inequalities have widened overall, life expectancy has stalled, and the amount of time people spend in poor health has increased over the past decade. The situation is much worse for ethnic minority groups, which have higher rates of deprivation and poorer health outcomes..$^{42-47}$ Relative poverty is also correlated with lower quality education and a higher rate of criminal activity, thus limiting employment opportunities. ${ }^{9}$ However, black Americans have a lower life expectancy than white and Hispanic Americans, even if they have attained university degrees. ${ }^{48}$

Interventions to ameliorate the adverse effect of covid-19 must start with reducing and reversing the socioeconomic effects (box 3). In the UK, socioeconomic inequalities were worsened by changes to the labour market, social security system, immigration policy, and insecure employment. 49

\section{Box 3: Mitigating the ethnic disparities in covid-19 and beyond ${ }^{19} 3344$}

- Increase recognition and awareness of ethnic disparities in health and healthcare among the general public, key stakeholders, healthcare providers, and healthcare professionals

- Governments and executive agencies should seek to understand why inequalities exist and how racism and structural discrimination affect people's lives and contribute to ethnic disparities

- Mandatory comprehensive data collection on ethnicity, through a health observatory or similar body, as part of routine health and social care delivery. Mandatory inclusion of ethnicity data at death certification

- Provision of that data to local and national care providers to identify and tackle health problems faced by ethnic minorities

- Development of legally binding, culturally competent, comprehensive occupational risk assessment tools that can be used to reduce the risk of employees' exposure to and acquisition of covid-19

- Provision of resources and support to businesses to ensure workplace safety, and financial support packages to ethnic minority individuals in low paid, insecure employment

- Ethnic minority groups must be included in the extremely vulnerable category for covid-19 and where the risk is high, employees must be supported through flexible work environments such as non-public facing roles and redeployed away from covid-19 areas wherever possible

- Improve access, experiences, and outcomes of health and social care by reducing variations around best practices. These include promoting equity of care through evidence-based guidelines and providing incentives to enhance patient-provider communication and trust. Regular health impact assessments, equity audits, and better representation of ethnic minority communities among staff

- Increase the proportion of people from under-represented minorities among health professionals, removing barriers to their progression, including differential attainment in medical education and reform of assessment methods at undergraduate and postgraduate levels that are prone to ethnic bias. Increasing the representation of ethnic minorities in leadership at all levels

- Reducing inequalities caused by socioeconomic factors that disproportionately affect ethnic minorities, and implementation of economic policies that tackle poverty, unemployment, and poor housing

- Leadership on tackling institutional racism with a clear vision, accountability, and commitment for all organisations across public and private sectors. Inclusion of diversity as a key performance indicator for all leaders in their annual appraisal. Changes to policies and processes with mandatory programmes supported by organisational leadership and rigorously monitored

- Fund and support research into the specific causes of disparities with the full participation of ethnic minority communities and development of programmes to reduce them

- Fund, develop, and implement programmes for prevention and education on covid-19 in partnership with ethnic minority communities and accelerate health promotion and disease prevention programmes for non-communicable diseases, including promoting physical activity, smoking cessation, healthy weight, mental wellbeing and effective management of chronic conditions such as diabetes, hypertension, and asthma

- In the UK, Public Health England should expand the Workforce Race Equality Standard to assess the effect of ethnic inequalities on health outcomes

Lack of information on ethnicity in UK health and social care data prevents an understanding of the extent of inequalities and disparities. In the US, New Zealand, and Australia, where such data are collected, they have revealed the multiple ways in which racism can adversely affect health and possible interventions to mitigate those effects. The NHS Race and Health Observatory in England was launched last year to investigate the effect of ethnicity on people's health. ${ }^{50}$ The recent announcement that ethnicity is to be recorded as part of the death certification process is a major step forward.

Covid-19 should be seen in the wider context of ethnic disparities and not treated in isolation. The mitigation measures must redress the root causes of these disparities as well as the more urgent task of protecting those ethnic groups most at risk of adverse outcomes from covid-19 (box 3).

\section{Tackling racism and discrimination}

Systemic problems such as racism require structural interventions ${ }^{51}$ and reforms across the broad spectrum of society, including in healthcare, education, employment, and the criminal justice system. In the US, targeted civil rights policies in the 1960s-1970s narrowed the economic gap between black and white people, reduced health inequities, and improved living conditions and socioeconomic opportunities. ${ }^{52}$

High quality early childhood programmes can reduce crime, raise earnings, and promote education. ${ }^{53}$ In one such programme, the Carolina Abecedarian Project (ABC), people in the intervention group had lower levels of cardiovascular and metabolic diseases in their mid-3os compared with controls, with the effects particularly strong for men. Other interventions, including community initiatives to build community capacity around racism, have potential health benefits. Similarly, cultural empowerment such as a place for cultural activities among native communities in Canada reportedly resulted in substantially lower rates of youth suicide. 54

Institutional interventions need concerted political and organisational leadership with funding and investment by the state. In the UK, despite successive reports and inquiries into ethnic disparities, ${ }^{44-46}$ the recommendations of these inquiries have either not been implemented or have fallen by the wayside.

The focus of most interventions on cultural racism has been on reducing the implicit or unconscious bias and enhancing cultural competence. Cultural competency interventions can improve staff knowledge, skills, and attitudes and healthcare access and usage. However, there is little evidence that these interventions improve health outcomes or affect health equity. ${ }^{55}{ }^{56}$ Health and 
socioeconomic benefits have also been shown with values affirmation (enhancing self-worth by reflecting on and writing about most important values such as religious values or relationship with family and friendship) and social belonging interventions (creating a sense of relatedness). 57

Changing policies and processes throughout organisations can reduce workplace discrimination. ${ }^{8}$ Research suggests that diversifying the healthcare workforce improves the performance of the entire healthcare system, and ethnic concordance between patient and a clinician has been associated with better health outcomes and higher levels of patient satisfaction. ${ }^{59} \mathrm{~A}$ broad range of affirmative action policies have been implemented over the past few decades to increase ethnic minority participation in higher education and senior roles. ${ }^{59}$ These programmes could be strengthened and supported further. The McGregor-Smith review in 2017 reported that people from ethnic minorities made up one in eight of the UK working age population but only $10 \%$ of the workforce and $6 \%$ of top management positions, with low employment (62.8\%) and substantial underemployment (15.3\%) compared with white workers. ${ }^{44}$ However, some early evidence suggests that the NHS Workforce Race Equality Standard initiative is increasing the number of ethnic minority staff in more senior positions. ${ }^{60}$

The tragedy of the covid-19 pandemic, recent events in the US, and the Black Lives Matter movement have brought into sharp focus the burning ethnic injustices in our societies. Many high income countries with legacies of slavery, imperialism, and colonialism have a moral duty to reckon with the past. We know the problems, and the solutions are mostly in front of us. We must act now.

\section{Key messages}

- Ethnic disparities in covid-19 are part of the historical trend of poorer health outcomes seen in marginalised ethnic groups

- Ethnic inequities in health are not accounted for by socioeconomic status alone

- Racism in its various forms is a fundamental cause and driver of ethnic differences in socioeconomic status, adverse health outcomes, and ethnic inequities in health

- Mitigating the impact of covid-19 and other health inequities in ethnic populations requires a recognition of the causes, a commitment to openness and honesty, leadership, and resources

Contributors and sources All authors contributed to the initial draft and agreed on the final manuscript. DRW is a global expert on the effects of race on health and chair of the department of social and behavioural sciences at the University of Harvard. AM is a public health and primary care expert on chronic disease management (diabetes and cardiovascular disorders), health policy, and healthcare delivery. AE has written extensively on race and ethnicity in medicine and the medical profession. HK is a junior doctor with an interest in ethnicity in medicine. MSR is an academic clinical fellow with an interest in the wider impact of covid-19. This article uses the best available evidence including recent research papers, published inquiry reports, and expert opinion. MSR is the guarantor.

Patient and public involvement: An ethnic minority patient read the manuscript and provided feedback.

Competing interests: We have read and understood BMJ policy on declaration of interests and have no interests to declare.

Provenance and peer review: Not commissioned; externally peer reviewed.

AM is supported by the NIHR NW London Applied Research Collaboration. The views expressed in the article are those of the authors. We thank Dipesh Gopal for his feedback.

Netuveli G, Hurwitz B, Levy M, etal. Ethnic variations in UK asthma frequency, morbidity, and health-service use: a systematic review and meta-analysis. Lancet 2005;365:312-7. doi: 10.1016/S0140-6736(05)17785-X pmid: 15664226

2 McManus S, Bebbington P, Jenkins R, etal. Mental health and wellbeing in England: adult psychiatric morbidity survey 2014. NHS Digital, 2016.
3 Byrne B, Alexander C, Khan O, Nazroo J, Shankley W. Ethnicity, race and inequality in the UK: state of the nation. Policy Press, 2020.

4 Department of Experimental Psychology, Department of Social Medicine for the Health and Safety Executive. The scale of occupational stress: the Bristol Stress and Health at Work Study. HSE Books, 2000.

5 Arias E, Xu J, Jim MA. Period life tables for the non-Hispanic American Indian and Alaska Native population, 2007-2009. Am J Public Health 2014;104(Suppl 3):S312-9. doi: 10.2105/AJPH.2013.301635 pmid: 24754553

6 Williams DR. Miles to go before we sleep: racial inequities in health. J Health Soc Behav 2012;53:279-95. doi: 10.1177/0022146512455804 pmid: 22940811

Public Health England. Disparities in the risk and outcomes of covid-19. PHE, 2020.

8 Paradies Y, Ben J, Denson N, etal. Racism as a determinant of health: a systematic review and meta-analysis. PLoS One 2015;10:e0138511. doi: 10.1371/journal.pone.0138511 pmid: 26398658

9 Williams DR, Lawrence JA, Davis BA. Racism and health: evidence and needed research. Annu Rev Public Health 2019;40:105-25.

doi: 10.1146/annurev-publhealth-040218-043750 pmid: 30601726

10 Public Health England. Local action on health inequalities: understanding and reducing ethnic inequalities in health. PHE, 2018.

11 Harding S, Read UM, Molaodi OR, etal. The Determinants of young Adult Social well-being and Health (DASH) study: diversity, psychosocial determinants and health. Soc Psychiatry Psychiatr Epidemiol 2015;50:1173-88. doi: 10.1007/s00127-015-1047-9 pmid: 25861790

12 Intensive Care National Audit \& Research Centre (ICNARC). ICNARC report on COVID-19 in critical care. ICNARC, 2020.

13 Harrison EM, Docherty AB, Barr B, et al. Ethnicity and outcomes from covid-19: the ISARIC CCP-UK prospective observational cohort study of hospitalised patients Social Science Research Network, 2020. https://papers.ssrn.com/abstract=3618215

14 Raisi-Estabragh Z, McCracken C, Bethell MS, etal. Greater risk of severe COVID-19 in Black, Asian and Minority Ethnic populations is not explained by cardiometabolic, socioeconomic or behavioural factors, or by $25(\mathrm{OH})$-vitamin D status: study of 1326 cases from the UK Biobank. J Public Health (Oxf) 2020;42:451-60. doi: 10.1093/pubmed/fdaa095 pmid: 32556213

15 Cook T, Kursumovic E, Lennane S. Exclusive: deaths of NHS staff from covid-19 analysed. Health Service Journal 2020 Jun 21. https://www.hsj.co.uk/exclusive-deaths-of-nhs-staff-from-covid-19analysed/7027471.article

16 US Centers for Disease Control and Prevention. COVID-19 hospitalization and death by race/ethnicity. 2020.

hitps:/uww.codcgov/coronavins/2019-ncov/covid-data/investigations-discovery/hospitalization-death-by-raceethniaty.html

17 APM Research Lab. COVID-19 deaths analyzed by race and ethnicity. 21 Jun 2020 https://www.apmresearchlab.org/covid/deaths-by-race

18 Haque Z, Becares L, Treloar N. A Runnymede Trust and ICM Survey. Over-exposed and under-protected the devastating impact of covid-19 on black and minority ethnic communities in Great Britain. Runnymede, 2020.

19 Public Health England. Beyond the data: understanding the impact of covid-19 on BAME groups. 2020.

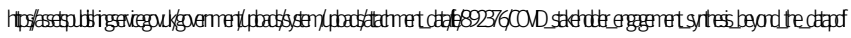

20 HM Government. Quarterly report on progress to address COVID-19 health inequalities. 22 Oct 2020.

https://www.gov.uk/govemment/publications/quarterly-report-on-progress-to-address-covid-19-health-inequalities

21 Stead M, Angus K, Langley T, et al. Mass media to communicate public health messages in six health topic areas: a systematic review and other reviews of the evidence. NIHR Journals Library, 2019. Public Health Research No 7.8. https://www.ncbi.nlm.nih.gov/books/NBK540706/

22 Bhala N, Curry G, Martineau AR, Agyemang C, Bhopal R. Sharpening the global focus on ethnicity and race in the time of COVID-19. Lancet 2020;395:1673-6. doi: 10.1016/S0140-6736(20)31102-8 pmid: 32401716

23 NHS Confederation. The impact of COVID-19 on BME communities and health and care staff. NHS Confederation, 2020.

24 MBRRACE-UK. Saving lives, improving mothers' care: lessons learned to inform maternity care from the UK and Ireland Confidential Enquiries into Maternal Deaths and Morbidity 2015-17. MBBRACE, 2019.

25 Modernising the Mental Health Act: Increasing choice, reducing compulsion; final report of the Independent Review of the Mental Health Act 1983. 2018.

hittps//Mww.gov.uk/govermment/publications/modemising-themental-health-adt-final-report-from-theindependentreview

26 Kaestner R, Pearson JA, Keene D, Geronimus AT. Stress, allostatic load and health of Mexican immigrants. Soc Sci Q2009;90:1089-111. doi: 10.1111/j.1540-6237.2009.00648.x pmid: 21165158

27 Williams DR. Race and health: basic questions, emerging directions. Ann Epidemiol 1997;7:322-33. doi: 10.1016/S1047-2797(97)00051-3 pmid: 9250627

28 Landrine H, Corral I, Lee JGL, Efird JT, Hall MB, Bess JJ. Residential segregation and racial cancer disparities: a systematic review. J Racial Ethn Health Disparities 2017;4:1195-205. doi: 10.1007/s40615-016-0326-9 pmid: 28039602

29 Cutler DM, Glaeser EL. Are ghettos good or bad?Q J Econ 1997;112:827-72doi: 10.1162/003355397555361

30 Brady D, Burton L. Oxford handbook of the social science of poverty. Oxford University Press, 2016. https://www.oxfordhandbooks.com/view/10.1093/oxfordhb/9780199914050.001.0001/oxfordhb-9780199914050 
31 UK Government. Ethnicity facts and figures. 30 Oct 2020. https://www.ethnicity-facts-figures.service.gov.uk/

32 Office for National Statistics. 2011 census. https://www.ons.gov.uk/peoplepopulationandcommunity/populationandmigration/populationestimates/bulletins/2011censuskeystatisticsforenglandandwales/2012-12-11\#ethnic-group

33 Smedley B, Stith A, Nelson A. Committee on understanding and eliminating racial and ethnic disparities in health care. unequal treatment: confronting racial and ethnic disparities in health care. National Academies Press, 2003.

34 Todd KH, Samaroo N, Hoffman JR. Ethnicity as a risk factor for inadequate emergency department analgesia. JAMA 1993;269:1537-9. doi: 10.1001/jama.1993.03500120075029 pmid: 8445817

35 Purnell TS, Calhoun EA, Golden SH, etal. Achieving health equity: closing the gaps in health care disparities, interventions, and research. Health Aff (Millwood) 2016;35:1410-5. doi: 10.1377/hthaff.2016.0158 pmid: 27503965

36 van Ryn M, Burgess DJ, Dovidio JF, etal. The impact of racism on clinician cognition, behavior, and clinical decision making. Du Bois Rev 2011;8:199-218. doi: 10.1017/S1742058X11000191 pmid: 24761152

37 Cooper LA, Roter DL, Carson KA etal. The associations of clinicians' implicit attitudes about race with medical visit communication and patient ratings of interpersonal care. Am J Public Health 2012;102:979-87. doi: 10.2105/AJPH.2011.300558 pmid: 22420787

38 Williams DR, Mohammed SA. Discrimination and racial disparities in health: evidence and needed research. J Behav Med 2009;32:20-47. doi: 10.1007/s10865-008-9185-0 pmid: 19030981

39 Williams DR, Lawrence JA, Davis BA, Vu C. Understanding how discrimination can affect health. Health Serv Res 2019;54(Suppl 2):1374-88. doi: 10.1111/1475-6773.13222 pmid: 31663121

40 Geronimus AT. The weathering hypothesis and the health of African-American women and infants: evidence and speculations. Ethn Dis 1992;2:207-21.pmid: 1467758

41 Anderson G, Frank JW, Naylor CD, Wodchis W, Feng P. Using socioeconomics to counter health disparities arising from the covid-19 pandemic. BM/2020;369:m2149. doi: 10.1136/bmj.m2149 pmid: 32513666

42 Social Metrics Commision. Measuring poverty 2020: a report of the Social Metrics Commission. 2020.

43 Department for Work and Pensions. Statistics on the number and percentage of people living in low income households for financial years 1994/95 to 2018/19. DWP, 2020.

44 UK Government. Race in the workplace: The McGregor-Smith review. UK Government, 2017.

45 UK Government. The Lammy Review: An independent review into the treatment of, and outcomes for, black, Asian and minority ethnic individuals in the criminal justice system. UK Government, 2017.

46 Cabinet Office. Race disparity audit: summary findings from the ethnicity facts and figures. Cabinet Office, 2017.

47 Institute of Health Equity. Health equity in England: the Marmot Review 10 years on. IHE, 2020

48 Braveman PA, Cubbin C, Egerter S, Williams DR, Pamuk E. Socioeconomic disparities in health in the United States: what the patterns tell us. Am J Public Health 2010;100(Suppl 1):S186-96. doi: 10.2105/AJPH.2009.166082 pmid: 20147693

49 Khunti K, Platt L, Routen A, Abbasi K. Covid-19 and ethnic minorities: an urgent agenda for overdue action. BMJ 2020;369:m2503. doi: 10.1136/bmj.m2503 pmid: 32576558

50 Rao M, Adebowale V. The NHS Race and Health Observatory-its time has come. BMJ Opinion, 17 Jun 2020. https://blogs.bmi.com/bmi/2020/06/17/the-nhs-race-and-health-observatory-itstime-has-come/

51 Williams DR. Purdie-Vaughns V. Needed interventions to reduce racia//ethnic disparities in health. J Health Polit Policy Law 2016;41:627-51. doi: 10.1215/03616878-3620857 pmid: 27127267

52 Hahn RA, Truman BI, Williams DR. Civil rights as determinants of public health and racial and ethnic health equity: Health care, education, employment, and housing in the United States. SSM Popul Health 2018;4:17-24. doi: 10.1016/.jssmph.2017.10.006 pmid: 29250579

53 Campbell F, Conti G, Heckman J), etal. Early childhood investments substantially boost adult health. Science 2014;343:1478-85. doi: 10.1126/science.1248429 pmid: 24675955

54 Chandler MJ, Lalonde C. Cultural continuity as a hedge against suicide in Canada's First Nations. Transcult Psychiatry 1998;35:191-219.doi: 10.1177/136346159803500202

55 Truong M, Paradies Y, Priest N. Interventions to improve cultural competency in healthcare: a systematic review of reviews. BMC Health Serv Res 2014;14:99 doi: 10.1186/1472-6963-14-99 pmid: 24589335

56 Horvat L, Horey D, Romios P, Kis-Rigo J. Cultural competence education for health professionals. Cochrane Database Syst Rev 2014;(5):CD009405. doi: 10.1002/14651858.CD009405.pub2. pmid: 24793445

57 Cohen GL, Sherman DK. The psychology of change: self-affirmation and social psychological intervention. Annu Rev Psychol 2014;65:333-71. doi: 10.1146/annurev-psych-010213-115137 pmid: 24405362

58 Kalev A, Dobbin F, Kelly E. Best practices or best guesses? Assessing the efficacy of corporate affirmative action and diversity policies. Am Sociol Rev 2006;71:589-617doi: 10.1177/000312240607100404

59 Williams DR, Cooper LA. Reducing racial inequities in health: using what we already know to take action. Int J Environ Res Public Health 2019;16:606. doi: 10.3390/ijerph16040606 pmid: 30791452

60 NHS. NHS workforce race equality standard. https://www.england.nhs.uk/about/equality/equalityhub/equality-standard/
This article is made freely available for use in accordance with BMJ's website terms and conditions for the duration of the covid-19 pandemic or until otherwise determined by BMJ. You may use, download and print the article for any lawful, non-commercial purpose (including text and data mining) provided that all copyright notices and trade marks are retained. 